\title{
Furcation Defects in Dogs Treated by Guided Tissue Regeneration (GTR)
}

Raul G. Caffesse, * Liza E. Dominguez, † Carlos E. Nasjleti, *Walter A. Castelli, $\neq$

Edith C. Morrison, * and Billy A. Smith†

THIS STUDY EVALUATED THE EFFECTS of guided tissue regeneration (GTR) in the treatment of Class II furcation defects in beagle dogs. Gore-Tex periodontal material was used, and the amount of furcation fill and the surface area corresponding to new connective tissue attachment and new bone were evaluated. If present, epithelium was also evaluated. Six female dogs with naturally-occurring periodontitis were given thorough root debridement. Four weeks later mucoperiosteal flaps were raised, involving the mandibular 2nd, 3rd, and 4th premolar and 1st molar teeth. After debridement, notches were placed on the roots at the level of furcal alveolar bone. Gore-Tex material was adapted to the furcation and secured with sutures on two teeth of each quadrant. The flaps were sutured tightly, making sure the margin of the material was covered. Teeth receiving only surgery acted as controls. Gore-Tex material was removed 1 month following surgery. All dogs were sacrificed by exsanguination at 3 months. Mesiodistal sections were evaluated by descriptive histology. Surface area determination of the furcal tissues was carried out using a microscope attached to a computerized digitizer. Approximately 10 serial sections per tooth were evaluated. Mean values for each dog were obtained for experimental and control teeth and analyzed using paired $t$-tests $(\mathrm{N}=6)$ to see whether different treatments had any effect on the parameters tested. Different degrees of fill were seen with epithelium, new connective tissue, and bone. Statistically, GTR gave significantly better results in the amount of connective tissue and bone fill achieved. $J$ Periodontol 1990;61:45-50.

Key Words: Tooth root/abnormalities; periodontal diseases/surgery; periodontitis/surgery; guided tissue regeneration.

The ultimate goal of periodontal therapy is the predictable regeneration of the periodontium at the site of previous periodontal breakdown; ${ }^{1}$ i.e., the formation of new cementum, new periodontal ligament, and new alveolar bone. The evidence available to date indicates that the most frequent mode of wound healing following surgical therapy is the development of a long junctional epithelium and connective tissue adhesion. ${ }^{2}$ It was suggested that a major reason for such healing is the capacity of gingival epithelial cells and fibroblasts to migrate and colonize the treated root surface faster than the periodontal ligament cells. ${ }^{3}$ It has also been suggested that repopulation of exposed root surfaces by periodontal ligament cells is a prerequisite for the regeneration of the periodontal attachment apparatus. ${ }^{4}$

*Department of Periodontics, Dental Branch, The University of Texas Health Science Center at Houston, TX.

$\dagger$ Department of Periodontics, The University of Michigan School of Dentistry, Ann Arbor, MI.

$\ddagger$ Department of Anatomy and Cell Biology, The University of Michigan Medical School, Ann Arbor, Ml.
Recent studies in experimental animals and humans have demonstrated that it is possible to favor the regeneration of a new connective tissue attachment to denuded root surfaces by a surgical procedure which is based on the principle of guided tissue regeneration (GTR). ${ }^{5-9}$ Nyman et al. ${ }^{5,6}$ reported that partial regeneration of periodontal tissues was obtained when a Millipore filter was interposed between the gingival tissue on one side and the exposed root surfaces and the supporting alveolar bone on the other. The role of the Millipore filter was two-fold: first, to serve as a barrier preventing the colonization of the exposed root surface by gingival cells; second, to allow selective repopulation of this surface by periodontal ligament cells. Results of these and other studies ${ }^{5-9}$ suggested that the formation of new attachment is related to the problem of guiding the growth of granulation tissue in such a way that the root surface becomes repopulated by those specific cells which possess the biological capacity of regenerating the attachment apparatus.

More recently, the case reports of Gottlow et al.,${ }^{10}$ Becker 
et al., ${ }^{11}$ Pontoriero et al., ${ }^{12}$ and Caffesse et al., ${ }^{13}$ coupled with animal studies, ${ }^{14,15}$ have generated major interest in the GTR technique-especially with the use of an expanded Teflon membrane rather than Millipore filters. Published studies have reported ${ }^{10-15}$ successful treatment of furcations and vertical defects after treatment with Teflon membranes. These membranes were effective in blocking epithelial downgrowth and gingival connective tissue proliferation, thereby promoting new attachment by allowing proliferation from the periodontal ligament.

The present study was designed to evaluate the potential for reformation of periodontal tissues in Class II furcation defects in beagle dogs when treated by guided tissue regeneration.

\section{MATERIALS AND METHODS}

Six purebred female beagle dogs with naturally-occurring periodontitis were used in this study and were maintained on a hard diet except for a 2-week period following surgery at which time a soft diet was used. All dogs presented with advanced periodontal disease involving the mandibular premolars and first molars. The dogs were sedated with an intramuscular injection of a $2.5 \%$ sodium thiamylal solution, and the teeth were thoroughly scaled and root planed. Subsequently, oral hygiene was maintained by daily brushing with a $0.12 \%$ chlorhexidine gluconate solution for 4 weeks prior to the surgical phase of treatment. For surgery, the animals were anesthetized, using sodium pentobarbital I.V. $(30 \mathrm{mg} / \mathrm{ml})$. A mucoperiosteal flap was raised, using a reverse bevel scalloped incision on the mandibular 2nd, 3 rd, and 4th premolars and 1st molars. Following removal of granulation tissue and complete root instrumentation, reference notches were placed in the roots at the level of the alveolar bone crest, using a number $1 / 2$ round bur. These notches were positioned on the buccal aspects of the roots and extended interproximally and into the furcation areas as deep as the involvement of the Class II furcation permitted (Fig. 1). Following the placement of the notches, the sites were thoroughly flushed with sterile saline and blotted dry with a sterile gauze sponge. Two teeth selected by the toss of a coin in each quadrant received the GoreTex§ periodontal material which was closely adapted over the furcation area and contoured to cover $2 \mathrm{~mm}$ to $3 \mathrm{~mm}$ of the alveolar bone crest. Once the periodontal material was in place, it was sutured, using a suspensory suture around each experimental tooth with a 4-0 Gore-Tex suture. Subsequently, interproximal silk sutures were placed through the flap resulting in a complete coverage of the material. The vertical releasing incisions were also sutured. The two teeth per quadrant which acted as controls were surgerized the same as the experimental teeth, but did not receive the Gore-Tex material. Moderate pressure was applied for 4 to 5 minutes with a sterile gauze moistened with sterile saline to minimize clot thickness and tissue gaping.

${ }^{5}$ W.L. Gore \& Associates, Flagstaff, AZ.

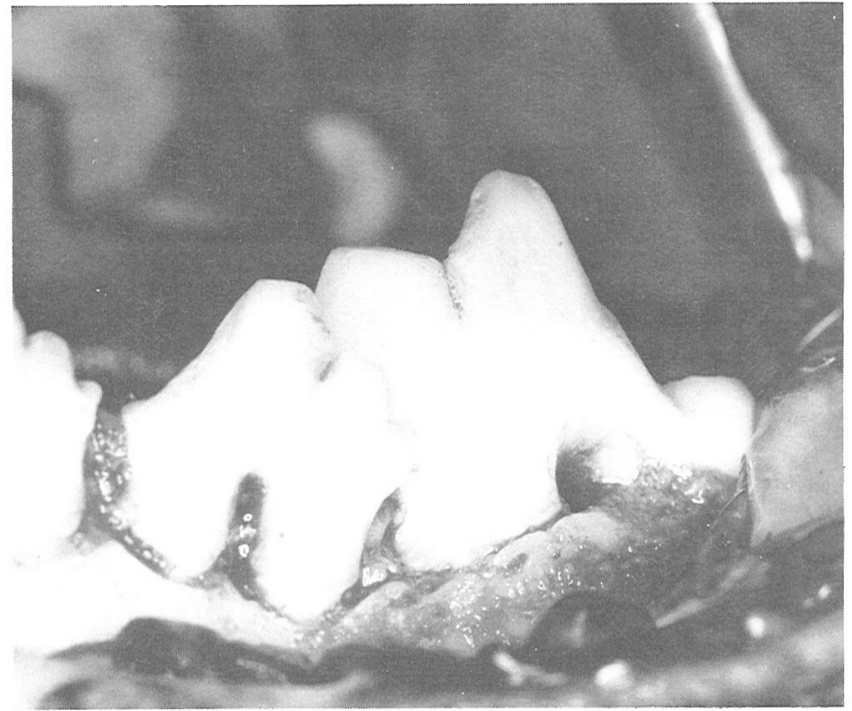

Figure 1: A mucoperiosteal flap has been elevated, the area debrided, and notches placed on the root at the level of the alveolar crest.

\section{Postsurgical Procedures}

During the 2 weeks following surgery, each dog was fed with a soft diet and water ad libitum. During the first week however, toothbrushing was suspended in order to prevent unnecessary disruption of the Gore-Tex material and healing flap. Seven days after surgery, the dogs were anesthetized with $7.5 \%$ sodium thyamilal which allowed for a rubber cup prophylaxis and photographs. One month after surgery, the Gore-Tex material was removed under general anesthesia using a split thickness flap procedure and suturing the tissues back after membrane material removal. A second surgical procedure was not undertaken on the control teeth. Three months after surgery, dogs were anesthetized with sodium pentobarbital for clinical examination and photographs. Following this, each dog was given additional anesthetic solution and sacrificed by exsanguination. The head of the animal was perfused with $10 \%$ neutral buffered formalin solution and then refrigerated for 24 hours. The jaws were dissected free, labelled, and placed in formalin for further fixation. The jaws were trimmed and then sectioned into appropriate segments and demineralized in EDTA solution. The demineralized tissue blocks were washed under running water for 24 hours, dehydrated in alcohol, infiltrated and embedded in paraffin, and serially sectioned in the mesiodistal plane into 6 micro sections. Every fifth section, cut $30 \mu \mathrm{m}$ apart, was placed on a glass microscopic slide and stained either with hematoxylin and eosin, Mallory's trichrome, or silver impregnation. Microscopic slides were examined under a Zeiss binocular microscope and descriptive histology and surface area determinations of the furcation areas were performed both in the experimental and control teeth.

For histologic description, a determination was done, including: 1) the presence or absence of root resorption and/ or dentoalveolar ankylosis; 2) the distribution of new ce- 


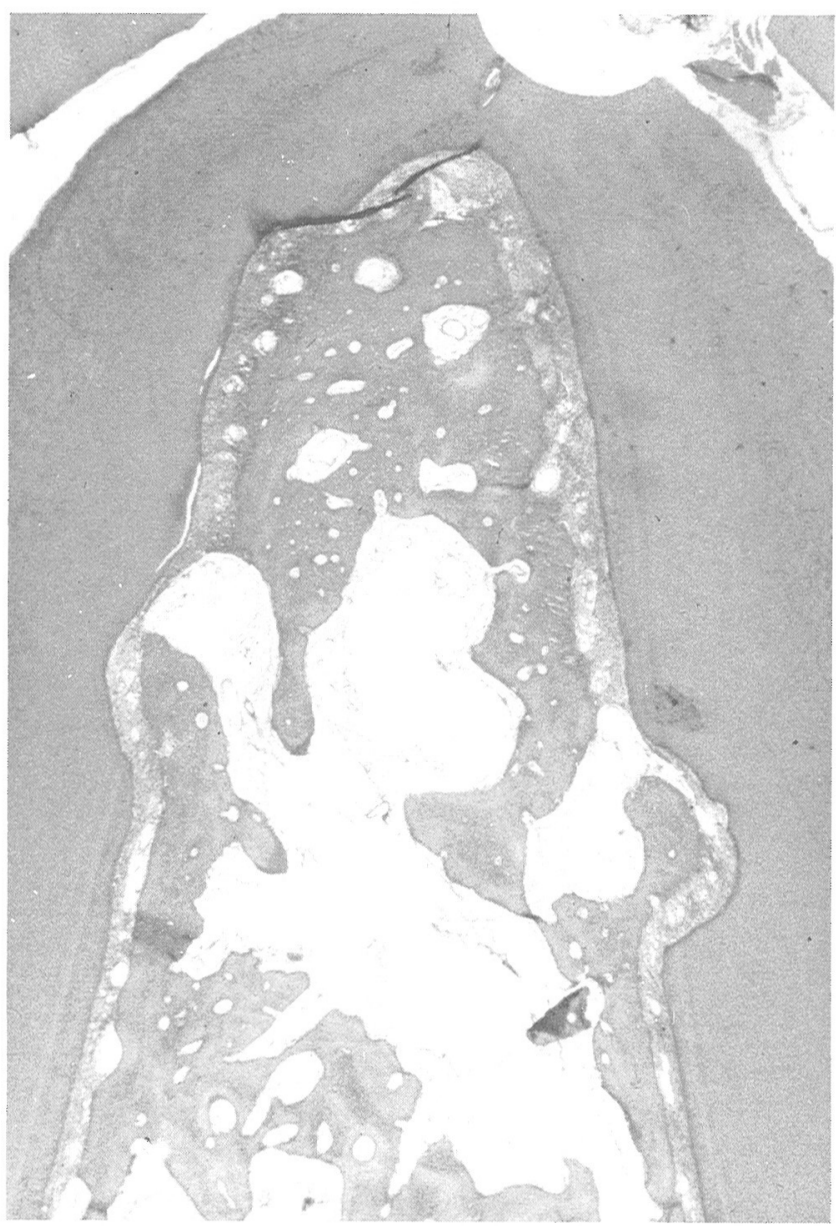

Figure 2A: Low-power view of an experimental specimen. It demonstrates significant amounts of new bone and new attachment without evidence of dentoalveolar ankylosis.

mentum deposition, if present; 3) the orientation of the periodontal fibers; and 4) the degree of inflammation in the tissues. Additionally, surface area determinations $\left(\mathrm{mm}^{2}\right)$ relative to the furcation were made evaluating: 1 ) the area occupied by epithelium plus connective tissue plus alveolar bone; 2) the area filled by connective tissue plus bone; 3 ) the area occupied by bone; and 4) the area occupied by epithelium. These determinations were made using a microscope attached to a computerized digitizer, as described previously. ${ }^{16}$ The examiner was unaware of the procedure performed to assure a blind evaluation. For each experimental and control tooth, 10 mesiodistal sections were evaluated, 80 sections per dog, 480 sections for the study. Mean values were obtained in each dog for experimental and control teeth, and the results were statistically analyzed, using the paired $t$-test, $(N=6)$, and the Wilcoxon Sign Rank test.

\section{RESULTS}

\section{Histologic Description}

For the most part, in the area adjacent to previously exposed furcation root surfaces, extensive connective tissue and al-

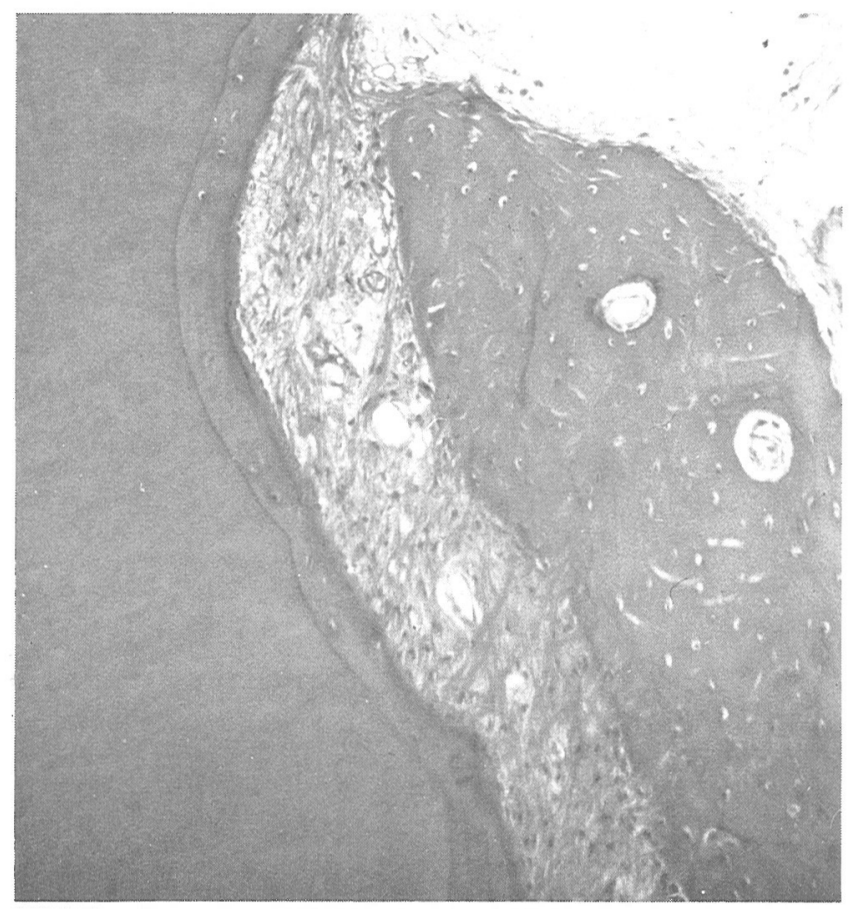

Figure 2B: $A$ higher-power view of an area of Figure $2 A$ showing new attachment, new alveolar bone, and new cementum deposition. $H \& E$ stain; original magnification $\times 250$.

veolar bone regeneration, as well as cementogenesis, resulted from surgery and the use of Gore-Tex periodontal material. New cementum with inserting collagen fibers, as well as tissue attachment uncomplicated by root resorption or dentoalveolar ankylosis was observed (Figs. 2A-E). Of the 24 experimental teeth evaluated, only one tooth depicted dentoalveolar ankylosis. Cementum and/or dentin resorption was minimal among these teeth. The majority of furcation defects treated by surgery only demonstrated some modest periodontal tissue regeneration. Coronal regrowth of alveolar bone was limited adjacent to control roots and signs of dentin resorption and/or dentoalveolar ankylosis were often found. Most frequently, these control specimens presented a hyperplastic epithelium in the coronal part of the furcation (Figs. 3A-C). This epithelium consisted of cords and masses of cells which were enclosing islands of inflammatory connective tissue. Some local metachromatic changes, as well as loss of cell nuclei, occurred at the superficial layers of the epithelium. In both experimental and control specimens, the connective tissue that showed inflammatory infiltrates was irregularly arranged into intertwining collagenous bundles. Some of these bundles were thin, indicative of young collagen formation; others were coarse with some hyalinized areas. The inflammatory infiltrates consisted predominantly of lymphocytes and occasional plasma cells. Eosinophils were absent from the fields.

Table 1 presents the results of the surface area determiantion, measured in $\mathrm{mm}^{2}$ of soft and hard tissues within the furcation, in both experimental and control specimens. The statistical analysis of the data demonstrated significant dif- 


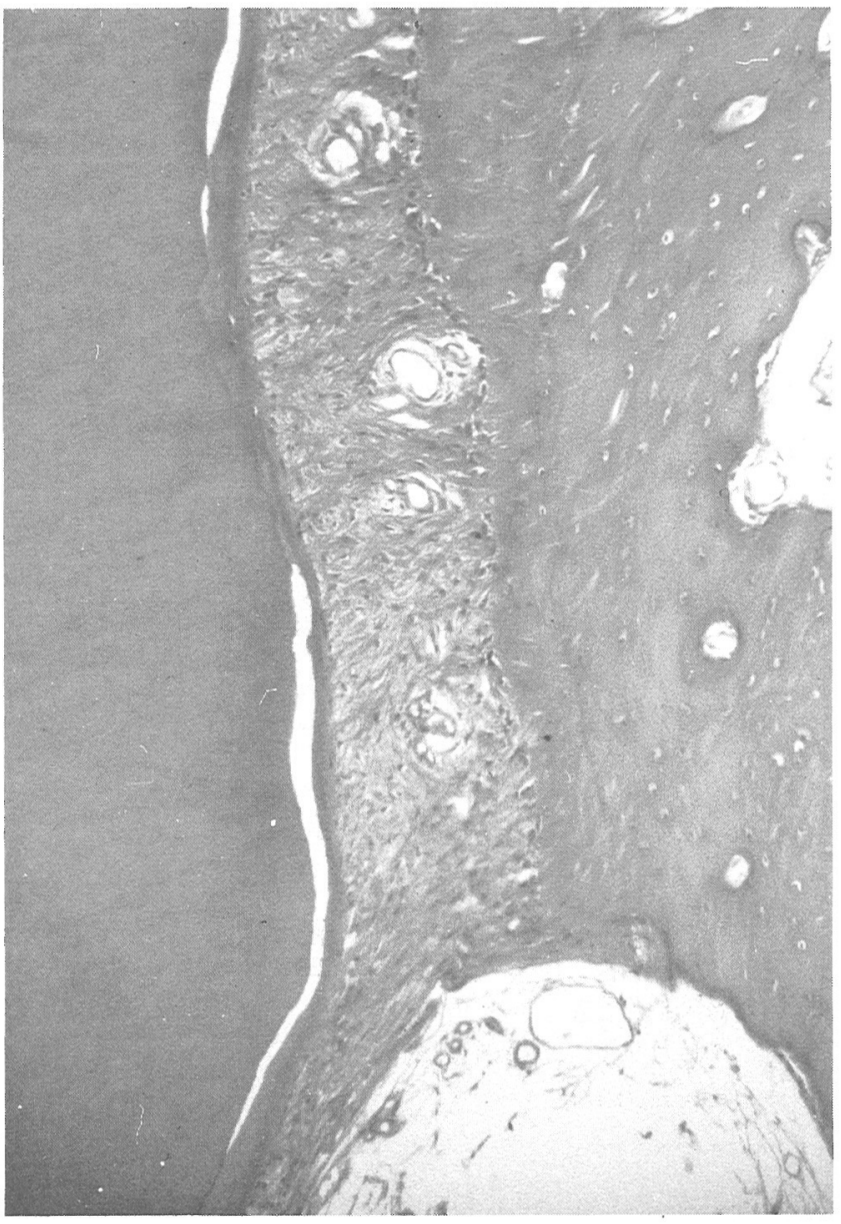

Figure 2C: $A$ higher-power view of an area of Figure $2 A$ demonstrating functionally oriented fibers as well as new bone growth. $H \& E$ stain; original magnification $\times 250$.

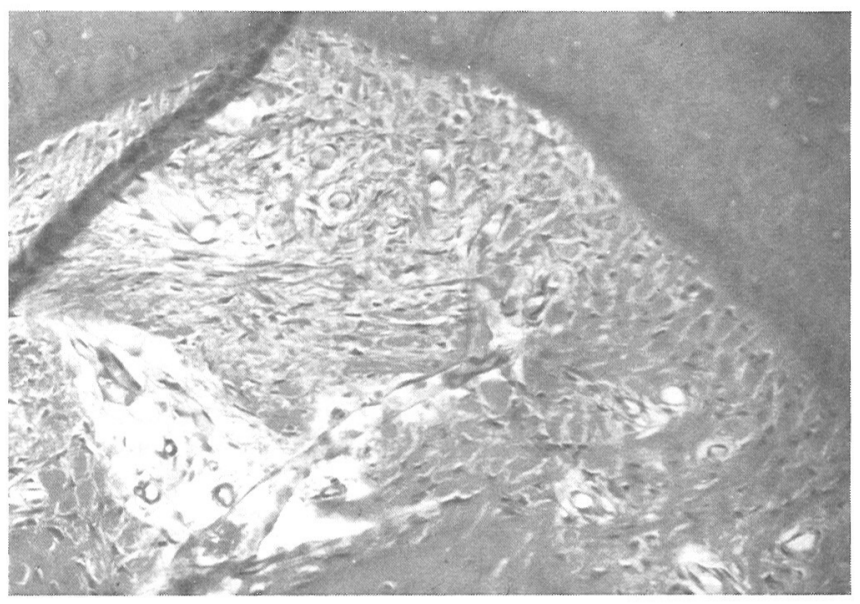

Figure 2D: A higher-power view of the furcation formix of Figure $2 \mathrm{~A}$ showing new connective tissue fibers between the new bone and the tooth. $H \& E$ stain; original magnification $\times 250$.

ferences $(P<0.05)$ favoring experimental areas both in the increase of regenerated connective tissue and in alveolar bone regrowth. Non-parametric analysis using the Wil-

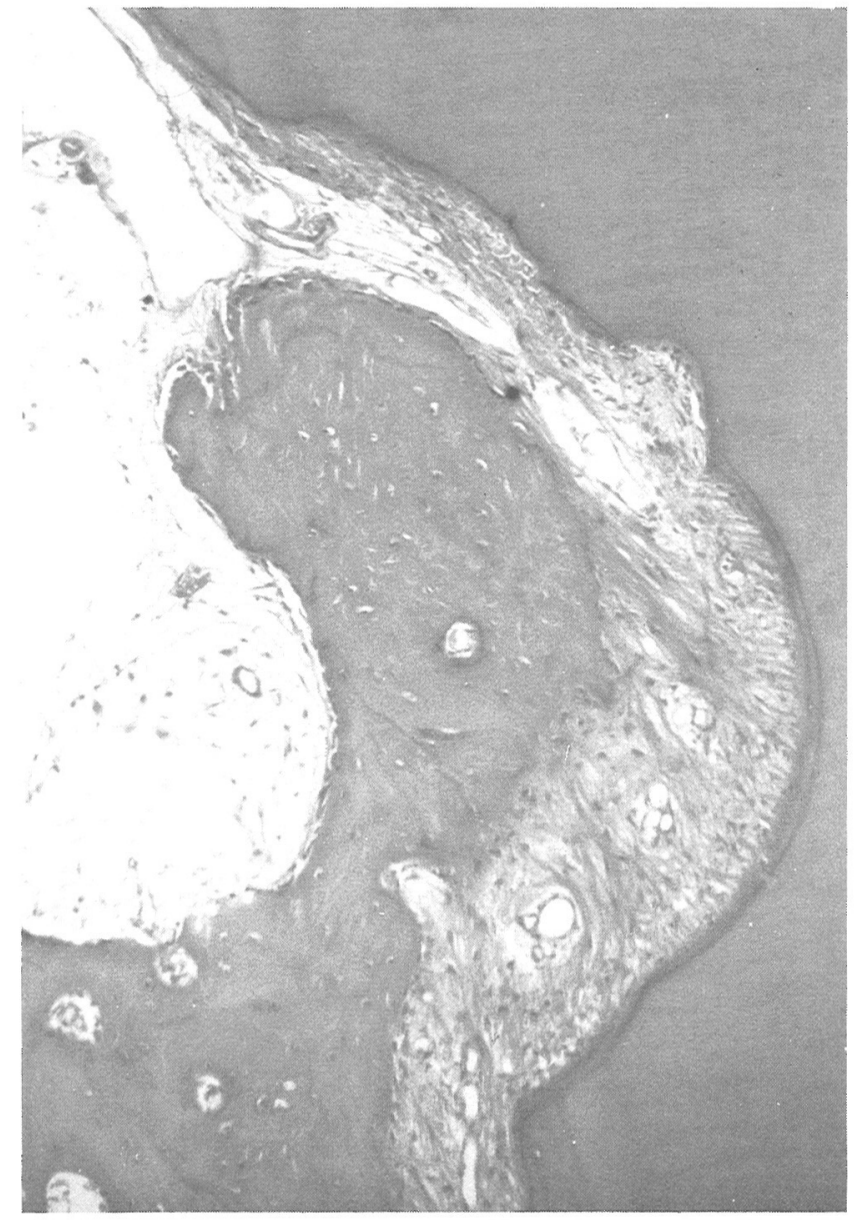

Figure 2E: A higher-power view of Figure $2 A$ demonstrating new cementum, bone, and connective tissue fiber arrangement. However, minor amounts of root resorption are evident at the coronal area of the notch. Original magnification $\times 250$.

coxon Sign Rank test provided similar results. Although not included in Table 1, newly formed cementum with inserting collagen fibers was consistently observed in experimental teeth. Whereas, new cementum formation was extremely limited in the controls. In the majority of control roots a long junctional epithelium was lining the root surface.

\section{DISCUSSION}

The present study was designed to evaluate the regenerative potential of the periodontal tissues in Class II furcation defects of mandibular premolar and molar teeth in beagle dogs. The findings of the study demonstrated that treatment of these defects, using a procedure in compliance with the principles of GTR, at most sites, resulted in significant increase in connective tissue and alveolar bone regeneration. These results agree with previous reports. Recent studies in experimental animals and humans have demonstrated that it is possible to favor the regeneration of a new connective tissue attachment to denuded root surfaces by using the GTR model which permits coronal regrowth of the periodontal ligament..$^{5-15}$ In our study, extensive connective tis- 


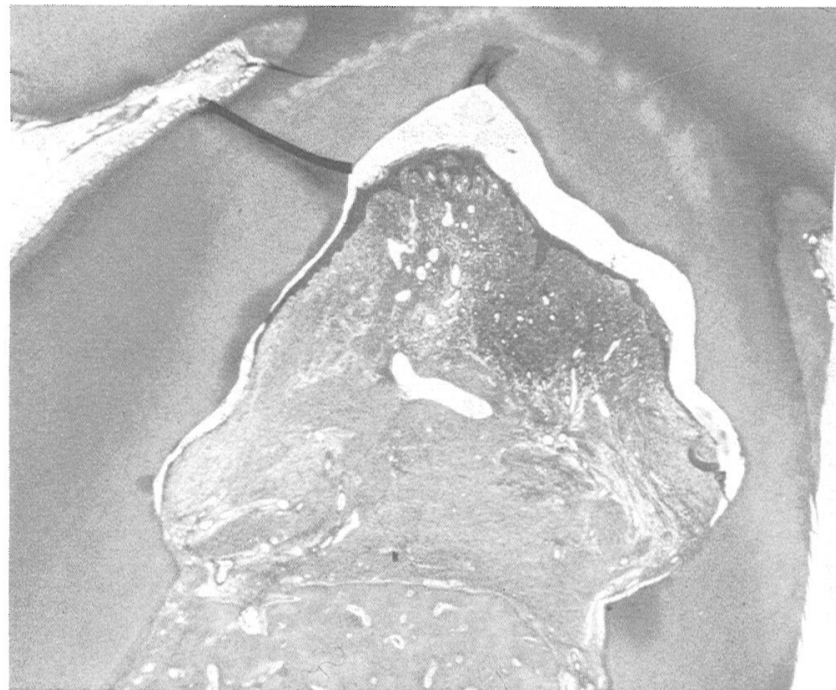

Figure 3A: Low-power view of a control specimen. Frequently, these specimens presented a hyperplastic epithelium in the coronal part of the furcation. This epithelium consisted of cords and masses of cells which were enclosing islands of inflammatory connective tissue.

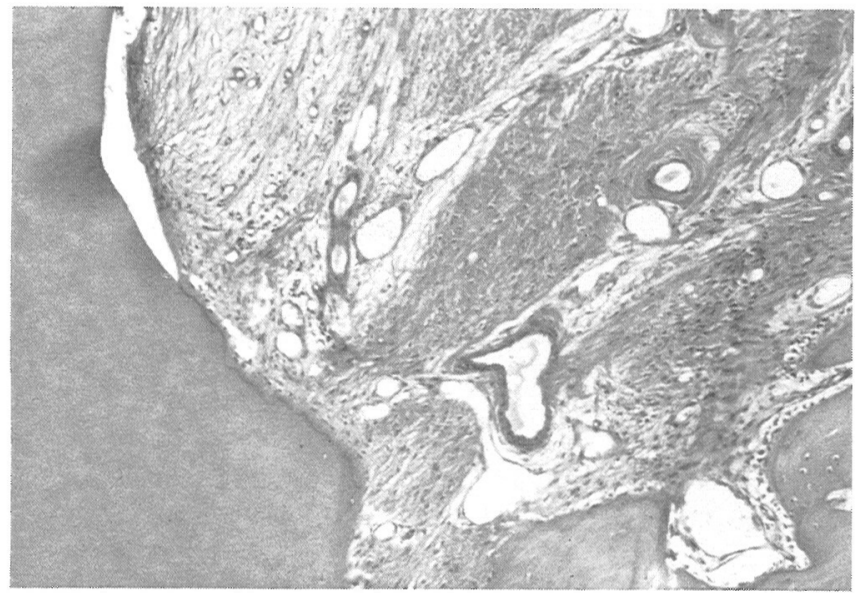

Figure 3B: A higher-power view of an area of Figure $3 A$ demonstrating some, but modest, periodontal tissue and bone regeneration.

sue and bone regeneration resulted with the use of GoreTex periodontal material, which allowed periodontal ligament cells to repopulate, but prevented cells from the gingival epithelium and the gingival connective tissue to repopulate the wound area adjacent to previously exposed furcation root surfaces.

Using GTR procedure in monkeys, Gottlow, et al. ${ }^{8}$ examined whether new connective tissue attachment formed on root surfaces previously exposed to plaque. Millipore filter or Gore-Tex periodontal membranes were used as physical barriers. Results showed that new cementum with inserting collagen fibers was observed on the previously exposed root surfaces of both experimental and control specimens. Test root surfaces, however, exhibited considerably more new cementum and fibrous attachment than controls, indicating that the placement of the barrier favored

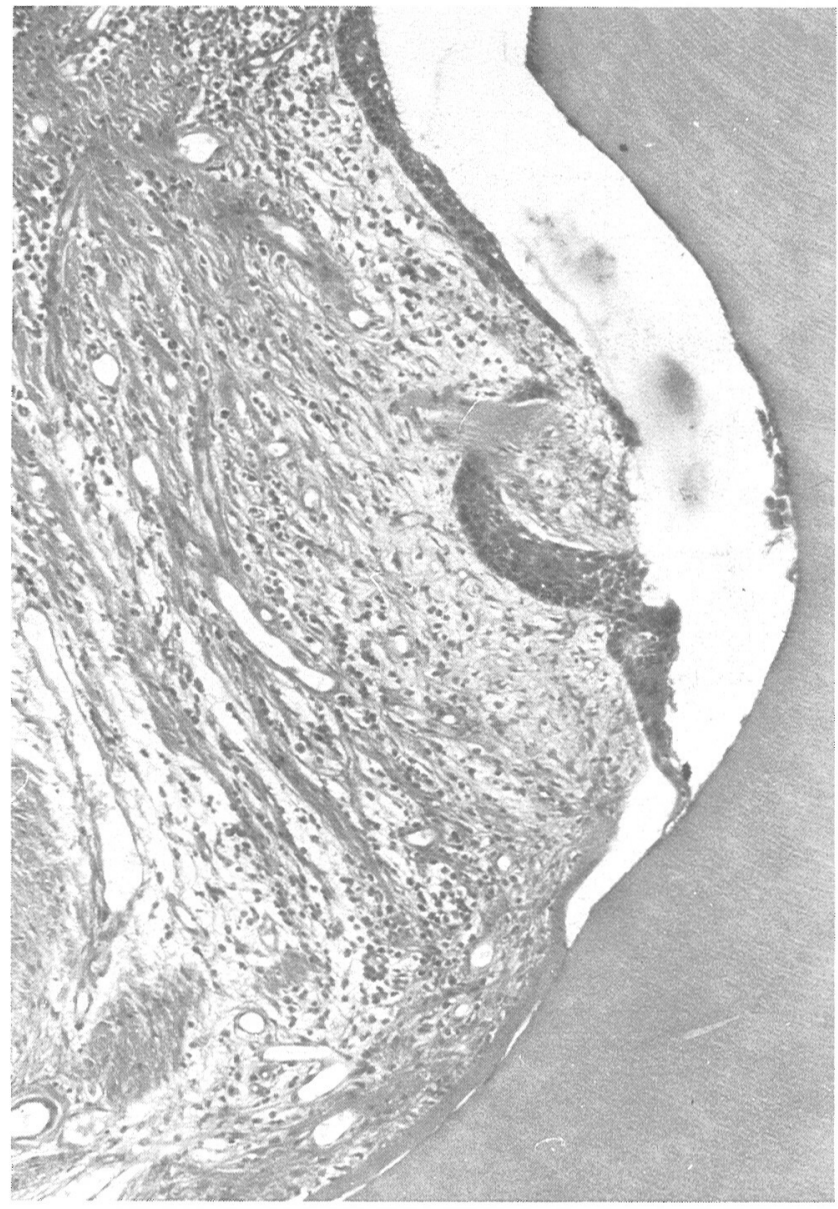

Figure 3C: A higher-power view of an area of Figure $3 A$ showing a long junctional epithelium extending almost to apical end of the notch. Note also limited amount of new cementum deposition.

the repopulation of the wound area adjacent to the roots by cells originating from the periodontal ligament. Similar results were obtained by Aukhil et al. ${ }^{14}$ and Caffesse et al. ${ }^{15}$ following the use of the GTR procedure in beagle dogs.

In humans, Gottlow et al. ${ }^{10}$ used Gore-Tex periodontal material to isolate root surfaces from gingival epithelium and connective tissue. Clinical measurements demonstrated decreasing probing depth and gains in clinical attachment levels for treated furcations and vertical defects. Biopsies of test sites depicted new cementum with inserting collagen fibers and varying amounts of new alveolar bone. Pontoriero et al., ${ }^{12}$ also in compliance with the principles of the GTR procedure, treated Class II furcation defects in humans and reported that at most sites it resulted in the disappearance of the anatomical defect. More than $90 \%$ of the sites treated with the GTR procedure showed complete resolution of the furcation problem. Conventional therapy, however, reached the same treatment goal in less than 20\% of the cases treated. Similarly, Becker et al. ${ }^{11}$ and Caffesse et al. ${ }^{13}$ treated furcation defects using the GTR procedure and the Gore-Tex periodontal material. These authors reported good, encouraging results, but not as good as those reported by 
Table 1: Furcation Fill Achieved in Beagle Dogs (Measured in $\mathbf{m m}^{2}$ )

\begin{tabular}{|c|c|c|c|c|c|c|}
\hline$N=6$ & $\begin{array}{l}\text { Mean } \\
\text { Control }\end{array}$ & $\begin{array}{c}\text { Mcan } \\
\text { Experimental } \\
\end{array}$ & $\bar{\Delta}$ & SD & $\begin{array}{c}\text { Paired } \\
t \text {-test }\end{array}$ & Significance \\
\hline$E p+C T+B$ & 1.94 & 3.38 & 1.44 & 1.13 & 3.12 & $P<.05$ \\
\hline$C T+B$ & 1.51 & 2.75 & 1.24 & 1.26 & 2.41 & $P<.05$ \\
\hline B & .44 & .91 & .47 & .45 & 2.61 & $P<.05$ \\
\hline Ep & .44 & .63 & .19 & 1.09 & .43 & NS \\
\hline
\end{tabular}

Degrees of Freedom $=5 ; \bar{\Delta}=$ Mean Difference; SD = Standard Deviation: NS $=$ Not Significant; $\mathrm{Ep}=$ Epithelium; $\mathrm{CT}=$ Connective tissue; $\mathrm{B}=$ Bone.

Pontoriero et al. ${ }^{12}$ An apparent explanation for the slightly different results cannot be offered, apart from the possible impact of the plaque control program in which the patients were enrolled following surgical treatment. In the Pontoriero et al. ${ }^{12}$ study the patients were maintained on a plaque control program which included professional tooth cleaning and oral hygiene instruction once every 2 weeks for a period of 6 months after healing following the surgical procedures.

The present study showed that root resorption and dentoalveolar ankylosis were minimal on curetted roots treated with the GTR procedure. This observation may indicate that repopulation of the treated root surfaces by cells originating from the periodontal ligament is needed to prevent root resorption and dentoalveolar ankylosis. The validity of this interpretation is consistent with the trends promoted by using the GTR procedure..$^{5-10}$ It has been postulated that the primary source of cells that repopulate the curetted root surface will determine the results. If proliferation from the gingival connective tissue is allowed, resorption of the root may occur. If the response comes from the alveolar bone, the result may be dentoalveolar ankylosis. If epithelium is allowed to migrate, a long junctional epithelium will be established. Further, it has been proposed that cells of the periodontal ligament and their progeny exhibit the ability to inhibit osteogenesis. ${ }^{17}$ It has also been proposed that periodontal ligament cells and bone cells may be able to prevent each other from intruding into their respective domains. ${ }^{4}$

Despite the encouraging findings related to the Gore-Tex periodontal material when it is used alone in the surgical treatment of periodontitis, based on present knowledge, it is tempting to consider the possible beneficial effects of adjunctive therapy like bone grafting and/or the use of attachment proteins. In addition, experience needs to be gained from the GTR procedure to answer questions about predictability of connective tissue and alveolar bone regeneration, cementogenesis, and closure of different defects, including Class II lingual furcations, Class III furcations, and in cases of a vertical or angular pattern of bone loss. Future studies need to address and elucidate these issues.

\section{CONCLUSIONS}

Within the limits of this study it can be concluded that: 1) the application of GTR principles improved the modality of wound healing of Class II furcation defects, and 2) while an invasive epithelium was the predominant feature in control sites, new cementum, connective tissue, and alveolar bone regeneration were predominant in the experimental furcation sites.

\section{REFERENCES}

1. Stahl, SS. Repair potential of soft tissue-root interface. $J$ Periodontol 1977; 48:545.

2. Wirthlin MR. The current status of new attachment therapy. $J$ Periodontol 1981; 52:529.

3. Melcher AH. Healing of wounds in periodontium. In: Biology of Periodontium London, Academic Press, 1969:499-529.

4. Mclcher AH. On the repair potential of periodontal tissucs. $J$ Periodontol 1976; 47:256.

5. Nyman S, Gottlow J, Karring $T$, Lindhe J. The regencrative potential of the periodontal ligament. An experimental study in the monkey. $J$ Clin Periodontol 1982; 9:257.

6. Nyman S, Lindhe J, Karring T. Reattachment - new attachment. In: Texbook of Clinical Periodontology, Copenhagen, Munksgaard, 1984; 409-429.

7. Aukhil I, Simpson DM, Schaberg TV. An experimental study of new attachment procedure in beagle dogs. $J$ Periodont Res 1983; 18:643.

8. Gottlow J, Nyman S, Karring T, Lindhe J. New attachment formation as the result of controlled tissue regencration. $J$ Clin Periodontol $1984 ; 11: 494$.

9. Magnusson I, Nyman S, Karring T, and Egelberg, J. Connective tissue attachment formation following exclusion of gingival connective tissuc and epithclium during healing. J Periodont Res 1985; 20:201.

10. Gottlow J, Nyman S, Karring T, Wennstrom J. New attachment formation in the human periodontium by guided tissue regeneration. $J$ Clin Periodontol 1986; 13:604.

11. Becker W, Becker BE, Berg L, et al. New attachment after treatment with root isolation procedures: Report for treated class III and class II furcations and vertical osseous defects. Int $J$ Periodontics Restorative Dent 8(3):9, 1988.

12. Pontoricro R, Lindhe J, Nyman S, et al. Guided tissue regeneration in degree II furcation - involved mandibular molars. A clinical study. J Clin Periodontol 1988; 15:247.

13. Caffesse RG, Smith BA, Duff B, et al. Class II furcations treated by guided tissuc regeneration in humans. $J$ Dent Res 1989; 68 (Spec Issue): 263, Abstr 654.

14. Aukhil I, Pettersson E, and Suggs C. Guided tissuc regencration. An experimental proccdure in beagle dogs. J Periodontol 1986; 57:727.

15. Caffesse RG, Smith BA, Castelli WA, Nasjleti CE. New attachment achieved by guided tissue regeneration in beagle dogs. $J$ Periodontol 1988; 59:589.

16. Smith BA, Caffesse RG, Nasjleti CE, et al. Effects of citric acid and fibroncctin and laminin application in treating periodontitis. $J$ Clin Periodontol 1987; 14:396.

17. Melcher AH. Repair of wounds in the periodontium of the rat. Influence of periodontal ligament on osteogenesis. Arch Oral Biol 1970; 15:1183.

Send Ieprint requests to: Dr. Raul G. Caffesse, Department of Periodontics, The University of Texas Health Science Center at Houston, 6516 John Freeman Avenue, Houston, TX 77030.

Accepted for publication July 25, 1989. 